\title{
Urinary Monocyte Chemoattractant Protein-1 as A Diagnostic Marker of Lupus Nephritis
}

\author{
Gamal A. Tawfik, Eman A. Ghareeb, Waleed O. Abd El-Waheed, \\ Mohammed M. Keshawy* and Heba M. Zaki
}

Department of Internal Medicine, Nephrology Unit, Suez Canal University, Faculty of Medicine, Egypt

\begin{abstract}
Background: Lupus nephritis accounts for significant morbidity and mortality in patients with systemic lupus erythematosus (SLE). Many biomarkers for renal involvement in SLE have been suggested in Egyptian patients; one of them is Monocyte chemoattractant protein-1 (MCP-1) which is one of the key chemokines that has chemotactic effect for monocytes and macrophages to sites of inflammation and may share in the pathogenesis of lupus nephritis (LN). Aim: The study aimed at assessing the role of MCP-1 in the early diagnosis of lupus nephritis and to explore any correlation its levels with disease activity and renal status. Subjects and Methods: The study was done as a case control study where 60 SLE patients with lupus nephritis (30 patients with active $\mathrm{LN}$ and 30 patients with inactive $\mathrm{LN}$ ) in addition to 30 healthy volunteers as control group were enrolled in the study and MCP-1 levels was determined using ELISA technique. Results: Urinary MCP-1 levels in SLE studied patients' groups was significantly higher than its level in control group $(p=0.0001)$ and it was significantly higher in active $L N$ than in non-active $L N$ subgroups ( $P$ value $=0.0001)$. Conclusion: Urinary MCP-1 can be used as a marker for LN activity.
\end{abstract}

Keywords: SLE, Lupus nephritis, MCP-1

\section{Introduction}

Systemic lupus erythematosus (SLE) is an autoimmune disease that may affect multiple organ systems. One of the most serious complications of SLE is renal damage. It occurs in $40-70 \%$ of all patients ${ }^{(1)}$. Lupus nephritis (LN) accounts for significant morbidity and mortality in patients with systemic lupus erythematosus (SLE) ${ }^{(2,3)}$. Many biomarkers for renal involvement in SLE have been suggested in Egyptian patients(4-6). Monocyte chemoattractant protein-1 (MCP1) is one of the key chemokines that has potent chemotactic action for monocytes and macrophages to sites of inflammation ${ }^{(7)}$. The MCP-1 was significantly increased in Egyptian SLE patients especially those with an increased intima media thickness ${ }^{(8)}$. MCP-1 is produced by many cell types, including mesangial, podocyte, and monocyte cells in response to various proinflammatory stimuli such as tumor necrosis factor alpha (TNF- $\alpha$ ). These cells subsequently mediate tissue injury and contribute to the development of 
renal dysfunction(7). The Level of MCP-1 in urine was found to be significantly greater in patients with a renal flare than in patients with stable renal $(9,10)$. The aim of the study was to assess the role of urinary monocyte chemoattractant protein-1 (MCP-1) in the early diagnosis of lupus nephritis (LN) and to explore any correlation of its levels with disease activity and renal status.

\section{Patient and Methods}

The study was done as a case control study aiming at assessing the role of urinary MCP-1 in the early diagnosis of lupus nephritis and to correlate the levels with disease activity and renal status. 60 SLE patients with lupus nephritis attending the Suez Canal University hospitals outpatient's clinic were enrolled in the study (30 patients with active $\mathrm{LN}$ and $30 \mathrm{pa}$ tients with inactive $L N$ ) in addition to 30 healthy volunteers as control group. The studied population was subjected to detailed medical history , clinical examination and laboratory investigation where Systemic Lupus Erythematosus disease activity score (SLEDAI) assessment was used to define lupus activity in addition to basic laboratory investigation ; serological markers of activity (e.g.: $\mathrm{C}_{3}, \mathrm{C}_{4}$, $E S R \geq 100$ ), evidence of renal flare (e.g.; urinary sediments and 24 hour urinary protein excretion rate) which were done by an automated analyzer (COBAS INTEGRA 400 Automated Chemistry Analyzer) and urinary MCP-1 assay was done using the Quantikine ${ }^{\circledR}$ Human MCP-1 Immunoassay which is a 3.5-4.5-hour solid phase ELISA used for MCP-1 assay according to the manufacturer instruction. All laboratory work was done in SCU clinical pathology laboratory. Collected data was coded, entered, and analyzed using Statistical Package for the Social Sciences (SPSS) version 24 software for analysis. Differences between frequencies such as age, gender, clinical pattern, and severity, was compared using Chisquare or Fisher exact tests. Differences between means were compared by $\mathrm{t}$ test. Pearson correlation coefficient test was used to evaluate the inter-correlations between the studied variables. Logistic regression analysis of the dependent variable and other studied variables was performed. Statistical significance was considered at P-value $<0.05$ and highly significant at P-value $<0.01$. The study was conducted after the Suez Canal university, faculty of medicine ethical committee approval.

\section{Results}

The majority of the studied patients were females representing $93.3 \% \quad(n=56)$ and their mean age was 30.05 years. $76.67 \%$ $(n=46)$ of them lives in urban area. The most encountered comorbid conditions were hypertension (35\%), followed by CKD (6.67\%) and DM (5\%), while epilepsy, RHD and vasculitis accounts each for $3.33 \%$ and the least encountered comorbid was hypothyroidism (1.67\%). No statistically significant difference between both active and inactive SLE groups regarding age, sex or Comorbidities were found (Table 1). Regarding laboratory investigations, the mean blood levels of HB level was 11.14, TLC 7.55, Platelets 301, S. creatinine 1.36, albumin 2.89, C3 87.18, C4 16.94, CRP 8.32, ACR 1153.5. As regards urinary parameters the most encounter abnormalities were microscopic proteinuria (56.6\%) followed by microscopic hematuria (46.6\%). Fifty percent of the studied patients have high ESR and most of them have normal CRP. While, $56.6 \%$ has proteinuria and $46.6 \%$ has hematuria (Table 2). Urinary MCP-1 levels in overall SLE studied patients' groups was significantly higher than its level in control group (mean $0.68 \pm 0.51$ vs. $0.26 \pm 0.09$ 
respectively. $P=0.0001$ ) (Table 3). The mean levels of MCP-1 was significantly higher in active SLE $(1.03 \pm 0.48)$ than in non-active SLE ( $0.34 \pm 0.18)$ subgroups $(P$ $=0.0001 ; \mathrm{Cl} 95 \%$ ) (Fig. 1) and logistic regression analysis of urinary MCP-1 shows a significantly positive associated with $C_{3}(B=$
$1.01 ; p=0.0001), C 4(B=1.02 ; p=0.0001)$ and $A C R$ (Beta $=0.57 ; \mathrm{p}$ value 0.001 ). (Fig. 2a-c). ROC curve of urinary MCP-1 in LN patients had an $A U C=0.92(P=0.0001)$ and urinary MCP1 level of $0.43 \mathrm{mg} / \mathrm{dl}$ gives a sensitivity of $93.3 \%$ and specificity of $26.2 \%$ for identifying active LN. (Fig. 3).

Table 1. Sociodemographic characteristics of the patients

\begin{tabular}{|c|c|c|c|c|c|c|c|}
\hline \multirow[t]{2}{*}{ Characteristic } & \multicolumn{2}{|c|}{$\begin{array}{c}\text { Active LN } \\
\mathrm{n}=30\end{array}$} & \multicolumn{2}{|c|}{$\begin{array}{c}\text { Inactive LN } \\
\mathrm{n}=30\end{array}$} & \multicolumn{2}{|c|}{$\begin{array}{l}\text { Total } \\
\mathrm{N}=60\end{array}$} & \multirow[t]{2}{*}{$P$ value } \\
\hline & Freq. & $\%$ & Freq. & $\%$ & Freq. & $\%$ & \\
\hline $\begin{array}{l}\text { Gender } \\
\text { - Male } \\
\text { - } \quad \text { Female }\end{array}$ & $\begin{array}{c}2 \\
28\end{array}$ & $\begin{array}{l}6.67 \\
93.33\end{array}$ & $\begin{array}{c}2 \\
28\end{array}$ & $\begin{array}{l}6.67 \\
93.33\end{array}$ & $\begin{array}{c}4 \\
56\end{array}$ & $\begin{array}{l}6.67 \\
93.33\end{array}$ & 1 \\
\hline $\begin{array}{l}\text { Age (years) } \\
\qquad \quad \text { Mean } \pm \text { SD }\end{array}$ & \multicolumn{2}{|c|}{$30.83 \pm 7.09$} & \multicolumn{2}{|c|}{$29.26 \pm 9.46$} & \multicolumn{2}{|c|}{$30.05 \pm 8.33$} & 0.47 \\
\hline Residency & Freq. & $\%$ & Freq. & $\%$ & Freq. & $\%$ & \\
\hline $\begin{array}{l}\text { - Urban } \\
\text { - Rural } \\
\end{array}$ & $\begin{array}{c}27 \\
3\end{array}$ & $\begin{array}{l}90 \\
10\end{array}$ & $\begin{array}{l}19 \\
11\end{array}$ & $\begin{array}{l}63.33 \\
36.66\end{array}$ & $\begin{array}{l}46 \\
14\end{array}$ & $\begin{array}{l}76.67 \\
23.33\end{array}$ & $0.03 *$ \\
\hline $\begin{array}{ll}\text { Co morbid } \\
\text { - } \mathrm{HTN} \\
\text { - } \mathrm{DM} \\
\text { - Hypothyroidism } \\
\text { - } \text { Epilepsy } \\
\text { - } \text { CKD } \\
\text { - } \text { RHD } \\
\text { - Vasculitis }\end{array}$ & $\begin{array}{l}14 \\
0 \\
0 \\
2 \\
3 \\
1 \\
0\end{array}$ & $\begin{array}{c}46.66 \\
0 \\
0 \\
6.66 \\
10 \\
3.33 \\
0\end{array}$ & $\begin{array}{l}7 \\
3 \\
1 \\
0 \\
1 \\
1 \\
2\end{array}$ & $\begin{array}{l}23.33 \\
1 \\
3.33 \\
0 \\
3.33 \\
3.33 \\
6.66\end{array}$ & $\begin{array}{l}21 \\
3 \\
1 \\
2 \\
4 \\
2 \\
2 \\
\end{array}$ & $\begin{array}{c}35 \\
5 \\
1.67 \\
3.33 \\
6.67 \\
1.67 \\
1.67\end{array}$ & 0.52 \\
\hline
\end{tabular}

HTN= Hypertension; DM = Diabetes mellitus; $C K D=$ Chronic kidney disease; $R H D=$ Rheumatic heart disease

Table 2. Laboratory profile of the studied patients

\begin{tabular}{|c|c|c|}
\hline Items & Range & Mean \pm SD \\
\hline $\mathrm{HB}(\mathrm{g} / \mathrm{dl})$ & $7.9-14.7$ & $11.14 \pm 1.67$ \\
\hline TLC $($ cell x 103) & $3-17$ & $7.55 \pm 3.25$ \\
\hline Platelets $\left(\times 10^{3}\right)$ & $55-680$ & $301 \pm 110$ \\
\hline S. Creatinine $(\mathrm{mg} / \mathrm{dl})$ & $0.8-1.93$ & $1.36 \pm 0.56$ \\
\hline Albumin (g/dl) & $1.3-4.9$ & $2.89 \pm 0.89$ \\
\hline $\begin{array}{c}\text { Second hour ESR }(\mathrm{mm}) \\
\text { - } \quad \text { Elevated }(>100) \\
\text { - Normal }\end{array}$ & \multicolumn{2}{|c|}{$\begin{array}{c}n \% \\
3050 \\
3050\end{array}$} \\
\hline $\mathrm{C}_{3}(\mathrm{mg} / \mathrm{dl})$ & $23-182$ & $87.18 \pm 36.21$ \\
\hline $\mathrm{C}_{4}(\mathrm{mg} / \mathrm{dl})$ & $4-63$ & $16.94 \pm 11.61$ \\
\hline $\mathrm{CRP}(\mathrm{mg} / \mathrm{l})$ & $1.1-30$ & $8.32 \pm 6.52$ \\
\hline $\mathrm{ACR}(\mathrm{mg} / \mathrm{g})$ & $30-7000$ & $1153.5 \pm 1491$ \\
\hline $\begin{array}{ll}\text { Urine analysis } \\
\text { - } & \text { Pus (cell/HPF) } \\
\text { - } & \text { RBCS (cell/HPF) } \\
\text { - } & \text { Protein (mg/dl) } \\
\text { - } & \text { Cast }(+/-) \\
\end{array}$ & $\begin{array}{c}\text { Freq. }(\mathrm{n}=60) \\
17 \\
28 \\
34 \\
11 \\
\end{array}$ & $\begin{array}{c}\% \\
28.33 \\
46.67 \\
56.67 \\
18.33 \\
\end{array}$ \\
\hline
\end{tabular}


Table 3. Distribution of urinary MCP-1 levels in patients' groups against controls

\begin{tabular}{|l|c|c|c|c|}
\hline Parameter & $\begin{array}{c}\text { Overall patients } \\
(\mathrm{n}=60)\end{array}$ & $\begin{array}{c}\text { Controls } \\
(\mathrm{n}=30)\end{array}$ & T value & P value \\
\hline $\begin{array}{l}\text { Urinary MCP-1 }(\mathrm{mg} / \mathrm{dl}) \\
(\text { Mean } \pm \text { SD })\end{array}$ & $0.68 \pm 0.51$ & $0.26 \pm 0.09$ & 10.5 & $0.0001^{*}$ \\
\hline
\end{tabular}

* = significant

\section{Discussion}

Lupus nephritis is a frequent and serious complication of Systemic Lupus Erythematosus and is associated with considerable morbidity and mortality(3). Early detection of renal involvement during the course of SLE is important for improving the outcome $^{(11)}$. The ordinary serological markers used in clinical practice such as serum C3, $\mathrm{C}_{4}$ and anti-ds-DNA antibodies may be unreliable indicators of $\mathrm{LN}$ as they lack both sensitivity and specificity for prediction of active or relapsing LN. Moreover, serum creatinine is also an unreliable marker as significant kidney injury may occur before it rises ${ }^{(12)}$. Other urinary parameters like proteinuria and urinary sediments are also non-specific markers ${ }^{(13)}$ and therefore the need for finding such a marker is under research. So, our study aimed to assess the role of urinary MCP-1 as noninvasive biomarker predicting Lupus activity and determine its correlations with standard laboratory markers and disease activity indices. The present study showed that the mean levels of urinary MCP-1 in active SLE/ LN was significantly higher than the nonactive SLE / LN. This finding was the same in an earlier study by Tucci which examined the role of a functional MCP-1 polymorphism in SLE and LN. They showed that, $U$ MCP-1 values were significantly higher in patients with $\mathrm{LN}^{(14)}$. In another study investigating the urinary biomarker in SLE patients, they found that mean Urinary MCP1 levels in SLE renal flares, were significantly higher than its levels in non-renal

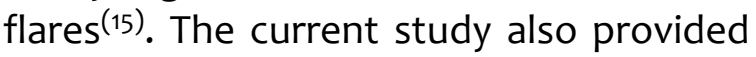
evidence that urinary MCP-1is significantly higher in SLE/ LN patients whether with active or non-active lesions when compared to healthy controls.

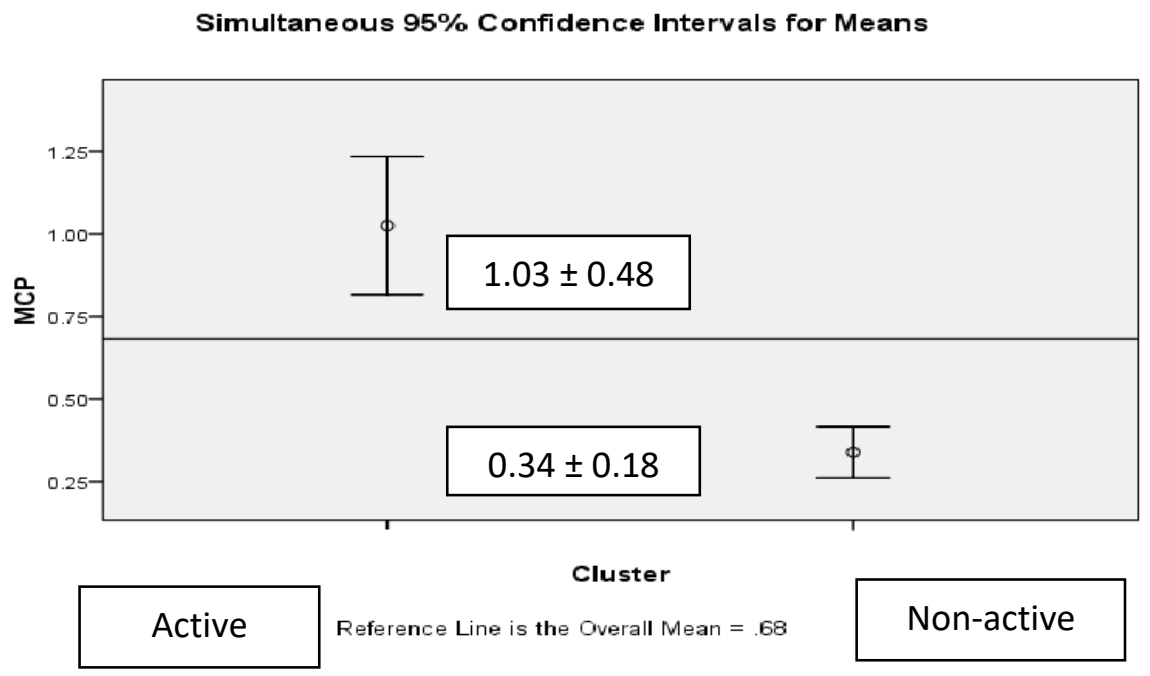

Figure 1. Cluster analysis of urinary MCP-1by disease activity status 


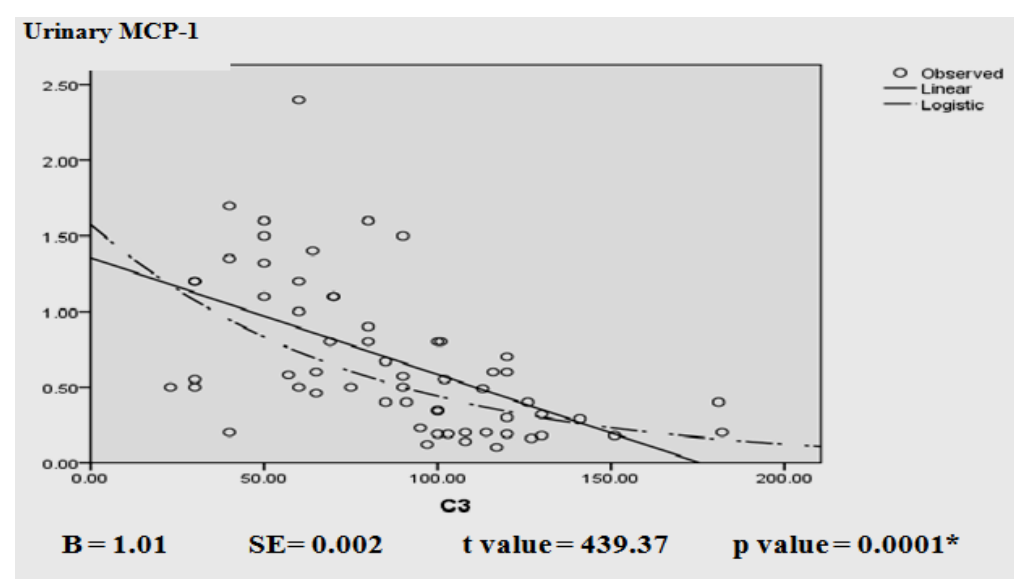

Figure 2a. Regression analysis of urinary MCP-1against $\mathrm{C}_{3}$

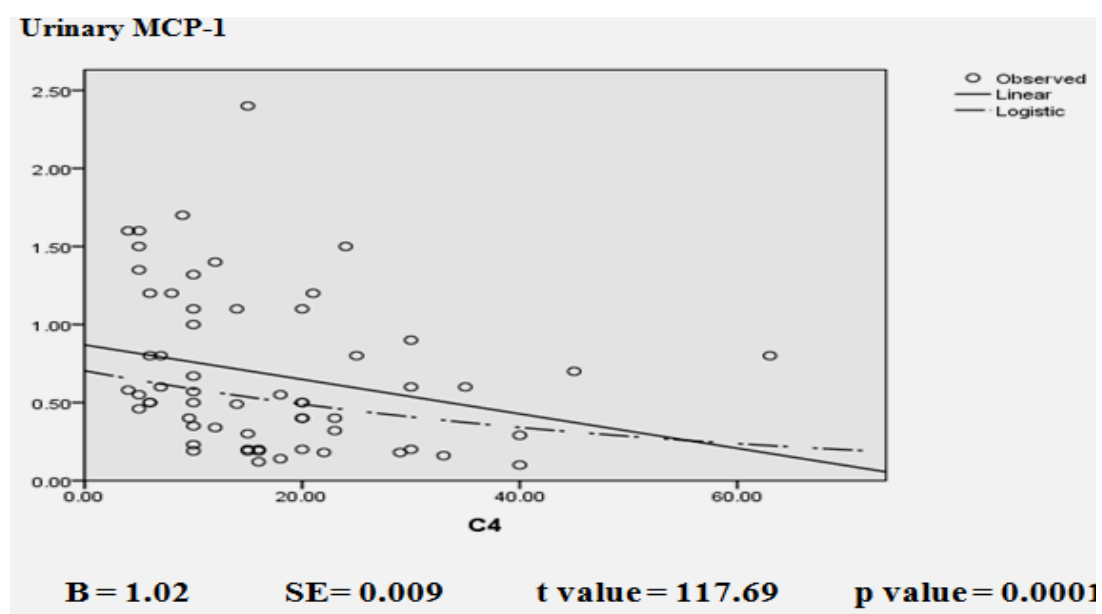

Figure $\mathbf{2 b}$. Regression analysis of urinary MCP-1against $\mathrm{C}_{4}$

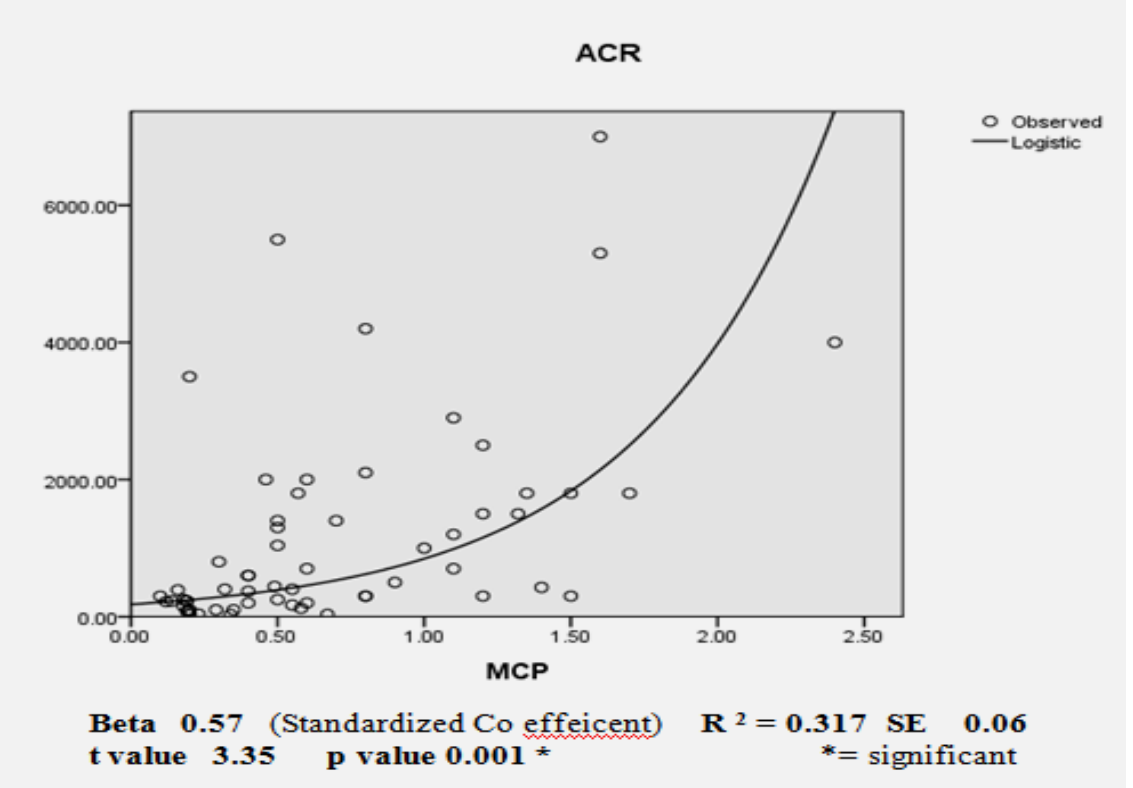

Figure 2C: Logistic regression analysis of urinary MCP-1 against $A C R$ 


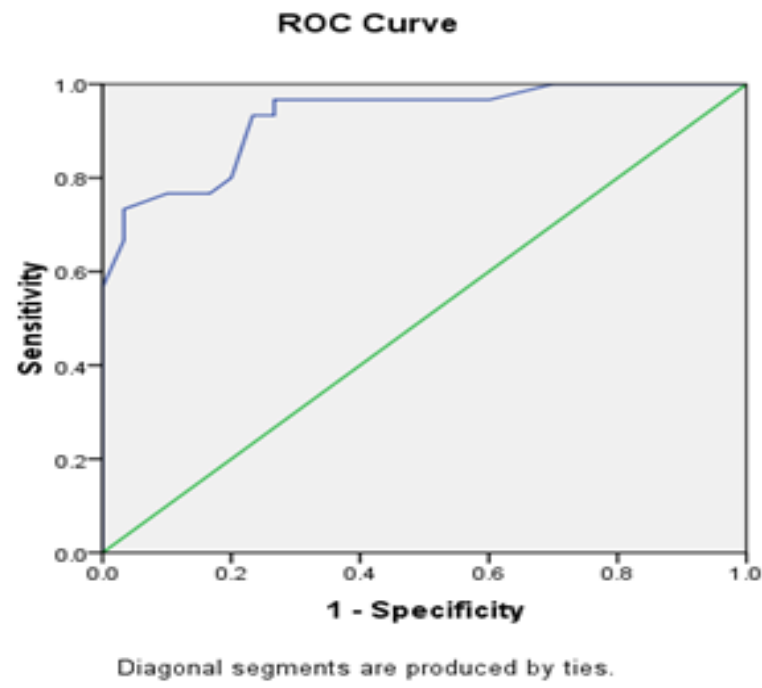

$\mathrm{AUC}=\mathbf{0 . 9 2}$

$\mathrm{SE}=\mathbf{0 . 0 3}$

$P$ value $=0.0001$ *

Figure 3: $\mathrm{ROC}$ curve of urinary MCP-1 in $\mathrm{LN}$ patients

This was the same in the study done in 2005 by Liu et al, where serum MCP-1 levels were measured in 112 patients with SLE, 30 patients with rheumatoid arthritis, 11 nonSLE patients with renal impairment, and 40 healthy volunteers. The expression of MCP-1 was significantly higher in active LN groups than in all other groups, and there was a close correlation between MCP-1 expression and the overall SLE disease activity index score and the SLE disease activity index renal score ${ }^{(16)}$. In Egypt, one earlier study showed urinary MCP-1 levels were significantly elevated in patients with active LN compared to those with inactive disease and control ${ }^{(17)}$. The associations between urinary MCP-1 excretion and serological lupus activity markers remain controversial. In the current study both $\mathrm{C}_{3}$ and C4 was significantly associated with urinary MCP-1 levels; the same finding was reported by after a 2 months follow up of $L N$ patients with renal flare ${ }^{(18)}$.Other studies reported the same finding like El-Shehaby et al. in 2011 found urinary MCP-1 levels to be associated with serum complements $C_{3}$ and $\mathrm{C}_{4}$ but not with anti-dsDNA Ab titers. Early in 2009 both Alzawawy et al.(crosssectional study, 30 SLE patients) and Kiani et al (longitudinal study, 87 SLE patients) reported that urinary $\mathrm{MCP}-1$ levels and antidsDNA positivity were highly associated ${ }^{(10,19)}$, whereas in 2014 Watson et al. in their longitudinal study involving 64 pediatric SLE patients reported an association between urinary MCP-1 and serum $\mathrm{C}_{3}{ }^{(20)}$. The present study showed that the increase of urinary ACR was met by increase of urinary MCP-1 and both were significantly associated with each other. In the same context, In 2004 the study by Tucci et al showed that urinary MCP-1 and 24-hr urinary protein excretion were positively correlated ${ }^{(14)}$. Furthermore, studying the glomerular expression of MCP-1 in SLE pediatric population revealed a correlation between increased glomerular MCP-1 expression and albuminuria ${ }^{(21)}$. In another study, a positive correlation between urinary excretion of MCP-1 and proteinuria was observed $^{(22)}$. Nevertheless, in contrast to the previous results; the early work of Dai et al in 2001 could not detect any correlation between urinary MCP-1 and urinary protein excretion in $\mathrm{LN}$ patients and the same finding was reported in the later work in 2012 by Mirfeizi and his colleagues(23,24). The ROC curve in the present study showed 
MCP-1 AUC $=0.92$ with $P=0.0001$ and Urinary $\mathrm{MCP} 1$ cutoff level of $0.43 \mathrm{mg} / \mathrm{dl}$ gives a Sensitivity of $93.3 \%$ and specificity of 26.2 $\%$ for identifying active LN. this is close to the results of Alharazy el at, in 2015 investigated urinary MCP-1 in relation to lupus nephritis activity in longitudinal manner during multiple patient visits and showed that at all time points, the ROC curves for urinary MCP-1 demonstrated it to be a good noninvasive biomarker for detection of $L N$ activity. AUCs at all visits were very good and ranged from 0.82 to 0.87 with sensitivities of $0.87-0.90$ and specificities of $0.61-0.79^{(18)}$. Also the earlier work of Torabinejad et al in 2012 in a mixed SLE/LN cohort reported that urinary MCP-1 had an AUC of 0.90 with a sensitivity of 0.94 and specificity of 0.80 for diagnosis of LN regardless of SLE activity at baseline ${ }^{(25)}$. But other studies suggest a higher cut-off point of $82 \mathrm{pg} / \mathrm{ml}$, Urinary MCP-1 with sensitivity of $88.5 \%$ and a specificity of $46.3 \%$ for identifying $\mathrm{LN}^{(24)}$. Amore investigation using renal pathology tissue showed that urinary MCP-1 had a sensitivity of $97 \%$ and a specificity of $100 \%$ in detecting active lupus nephritis and Glomerular MCP1 had a sensitivity of $64 \%$ and specificity of $95 \%$ while tubular MCP1 had a sensitivity of $4 \%$ and specificity of $20 \%$ in detecting active LN; Therefore, urinary and glomerular MCP-1 are more sensitive and specific for detection of activity of lupus nephritis ${ }^{(17)}$.

\section{Conclusion}

Urinary $\mathrm{MCP}-1$ can be used as a predictor or an adjunctive marker for LN activity and may identify early relapse of LN leading to earlier treatment and better outcome.

\section{Limitation of the study}

Certain limitations were encountered in this study which need to be addressed in the future. 1) The small sample size which may limit generalization of the study results hence a large population observational trial may be needed. 2) Using longitudinal study designs correlating multiple urinary MCP-1with multiple histological checkpoints using kidney biopsies and serological disease activity markers. And 3) Clinical trials investigating the ability of urinary MCP-1 in risk stratification of lupus nephritis is needed.

\section{Abbreviations}

LN: Lupus nephritis

MCP-1: Monocyte chemoattractant protein-1

SLE: Systemic lupus erythematosus SLE

SLEDAI: Systemic Lupus Erythematosus disease activity index

TNF-a: Tumor necrosis factor alpha

\section{References}

1. Faurschou $M$, Starklint $\mathrm{H}$, Halberg $\mathrm{P}$, Jacobsen S. Prognostic factors in lupus nephritis: diagnostic and therapeutic delay increases the risk of terminal renal failure. J. Rheumatol. 2006;33(8):1563-9.

2. Korbet SM, Lewis EJ, Schwartz MM, Reichlin M, Evans J, Rohde RD. Factors predictive of outcome in severe lupus nephritis. Lupus Nephritis Collaborative Study Group. Am J Kidney Dis. 2000;35(5):904-914

3. Reyes-Thomas J, Blanco I, Putterman C. Urinary biomarkers in lupus nephritis. Clin Rev Allergy Immunol. 2011;40(3):138-150.

4. El Bakry SA, Bader El-Din A, Al El Dakrony $\mathrm{HM}$, et al. Anti-nucleosome antibodies: a potential surrogate marker for renal affection in lupus patients with insignificant proteinuria. Egypt, Rheumatol 2014;36(2):79-84.

5. El-Gazzar II, Bahgat DMR, El Khateeb EM. IL22 in Egyptian SLE patients, could it reflect disease activity, skin or renal involvement or is it only an expensive ESR? Egy Rheumatol 2017;39(1):13-8. 
6. El-serougy $\mathrm{E}$, Ahmed $\mathrm{HH}$, Kamal MM, Niazy MH. The neuropeptide adrenomedullin, could it be linked to renal involvement and disease activity in systemic lupus erythematosus? Egypt Rheumatol 2015;37(4): S19-24.

7. Matrat A, Veysseyre-Balter C, Trolliet $P$, Villar E, Dijoud F, Bienvenu J, et al. Simultaneous detection of anti-C1q and anti-double stranded DNA autoantibodies in lupus nephritis: predictive value for renal flares. Lupus. 2011;20(1):28-34.

8. El-Saadany H, El-Sergany M, Kasem E, El-Batch MM, et al. Biochemical and genetic risk factors for atherosclerosis in systemic lupus erythematosus. Egypt Rheumatol 2011;33(1):35-43.

9. Rovin $B H$, Song $H$, Birmingham $D J$, Hebert LA, Yu CY, Nagaraja HN. Urine chemokines as biomarkers of human systemic lupus erythematosus activity. J Am Soc Nephrol 2005;16 (2):46773.

10. Kiani AN, Johnson K, Chen C, Diehl E, $\mathrm{Hu} \mathrm{H}$, Vasudevan $\mathrm{G}$, et al. Urine osteoprotegerin and monocyte chemoattractant protein-1 in lupus nephritis. J. Rheumatol. 2009;36 (10):2224-30.

11. Jill P. Buyon. Systemic Lupus Erythematosus A. Clinical and Laboratory Features. In: John H. Klippel, Primer on the Rheumatic Diseases 2008.p. 303-318.

12. Hewitt SM, Dear J, Star RA. Discovery of protein biomarkers for renal diseases. J Am Soc Nephrol 2004; 15:1677-89.

13. Brunner $H$, Mueller $M$, Rutherford $C$, Passo MH, Witte D, Grom A, et al. Urinary neutrophil gelatinase-associated lipocalin as a biomarker of nephritis in childhood-onset systemic lupus erythematosus. Arthritis Rheum 2006; 54:2577-84

14. Tucci M, Barnes EV, Sobel ES, Croker $B P$, Segal MS, Reeves WH, et al. Strong association of a functional polymorphism in the monocyte chemoattractant protein 1 promoter gene with lupus nephritis. Arthritis Rheum 2004; 50:1842-9

15. Rovin $B H$, Song $H$, Birmingham $D J$, Hebert LA, Yu CY, Nagaraja HN. Urine chemokines as biomarkers of human systemic lupus erythematosus activity. Clin Nephrol 2004; 16:467-73

16. Liu ZJ, Lin JY. Expression of monocyte chemoattractant protein-1 and lupus nephritis. Zhongguo Yi XueKeXue Yuan XueBao 2005; 27:491-5

17. Taha HA, Abdallah NH, Salem MN, Hamouda AH, AbdElazeem MI, Eesa NN . Urinary and tissue monocyte chemoattractant protein1 (MCP1) in lupus nephritis patients. Egy Rheumatologist 39 (2017) 145-150

18. Alharazy S, Kong NC, Mohd M, Shah SA, Ba'in A, Abdul Gafor AH. Urine Monocyte Chemoattractant Protein-1 and Lupus Nephritis Disease Activity: Preliminary Report of a Prospective Longitudinal Study. Autoimmune Dis. 2015; 2015:962046.

19. Alzawawy A, Zohary M, Ablordiny M, and Eldalie $M$, "Estimation of monocyte-chemoattractantprotein-1 (Mcp1) level in patients with lupus nephritis," Int J Rheumatic Dis, vol. 12, no. 4, pp. 311-318, 2009.

20. Watson L, Tullus K, Pilkington $C$ et al, "Urine biomarkers for monitoring juvenile lupus nephritis: a prospective longitudinal study," Pediatric Nephrology, vol. 29, no. 3, pp. 397-405, 2014

21. Marks SD, Williams SJ, Tullus K, Sebire NJ. Glomerular expression of monocyte chemoattractant protein-1is predictive of poor renal prognosis in pediatric lupus nephritis. Nephrol Dial Transplant 2008; 23: 3521-3526

22. Kim HL, Lee DS, Yang SH, Lim CS, Chung JH, Kim S, et al. The polymorphism of monocyte chemoattractant protein-1 is associated with the renal disease of SLE. Am J Kidney Dis 2002; 40:1146-52.

23. Dai C, Liu Z, Zhou H, Li L. Monocyte chemoattractant protein-1 expression in renal tissue is associated with 
monocyte recruitment and tubulo-interstitial lesions in patients with lupus nephritis. Chinese Med J 2001; 114: 864-868

24. Mirfeizi Z, Mahmoudi M, Naghibi M, et al. Urine Monocyte Chemoattractant Protein-1(UMCP-1) as a Biomarker of Renal Involvement in Systemic Lupus Erythematosus Iran. J Basic Med Sci, Vol. 15, No. 6, Nov-Dec 2012
25. Torabinejad S, Mardani R, Habibagahi $Z$ et al, "Urinary monocyte chemotactic protein-1 and transforming growth factor- $\beta$ in systemic lupus erythematosus," Indian J Nephrol, vol. 22, no. 1, pp. 5-12, 2012. 